\title{
HOW DESIGN QUIRKS AND CONDITIONS OF USE CONSPIRE TO STRUCTURAL FAILURE - A CASE STUDY
}

\author{
W. Ost ${ }^{1}$, J. Van Wittenberghe ${ }^{1}$ and P. De Baets ${ }^{1}$ \\ ${ }^{1}$ Ghent University, Laboratory Soete, Belgium
}

\begin{abstract}
Sometimes designers introduce a number of quirks in their design, either due to a preference for certain technologies or practices or under the influence of the policies in the companies they work for. While most of the time these quirks are harmless, sometimes they can, either in themselves or in combination with the conditions in which the design is used lead to failure. In this paper a case is discussed in which a designer used a quirky solution of lengthening an existing design of a $40 \mathrm{ft}$. freight container to $45 \mathrm{ft}$.. While the design in itself was not fundamentally flawed, it proved to be incompatible to the handling equipment still in use at most seaports.
\end{abstract}

Keywords Failure, container, design, conditions of use

\section{INTRODUCTION}

Worldwide the most popular freight containers are either 20 feet long (hence the term TEU or twenty feet equivalent unit) or 40 feet long. For transport by road in the European Union however the preferred size for freight containers nowadays is $45 \mathrm{ft}$. as this matches the maximum trailer length prescribed by the Highway Code. These $45 \mathrm{ft}$. freight containers however are ill matched to the equipment use to handle freight containers at seaports (designed to handle either 20ft. or $40 \mathrm{ft}$. freight containers). In this case study the failure of a certain type of $45 \mathrm{ft}$. container is discussed. Failure of the freight container resulted from the combination of a design quirk with ill-matched handling equipment.

\section{THE ACCIDENT}

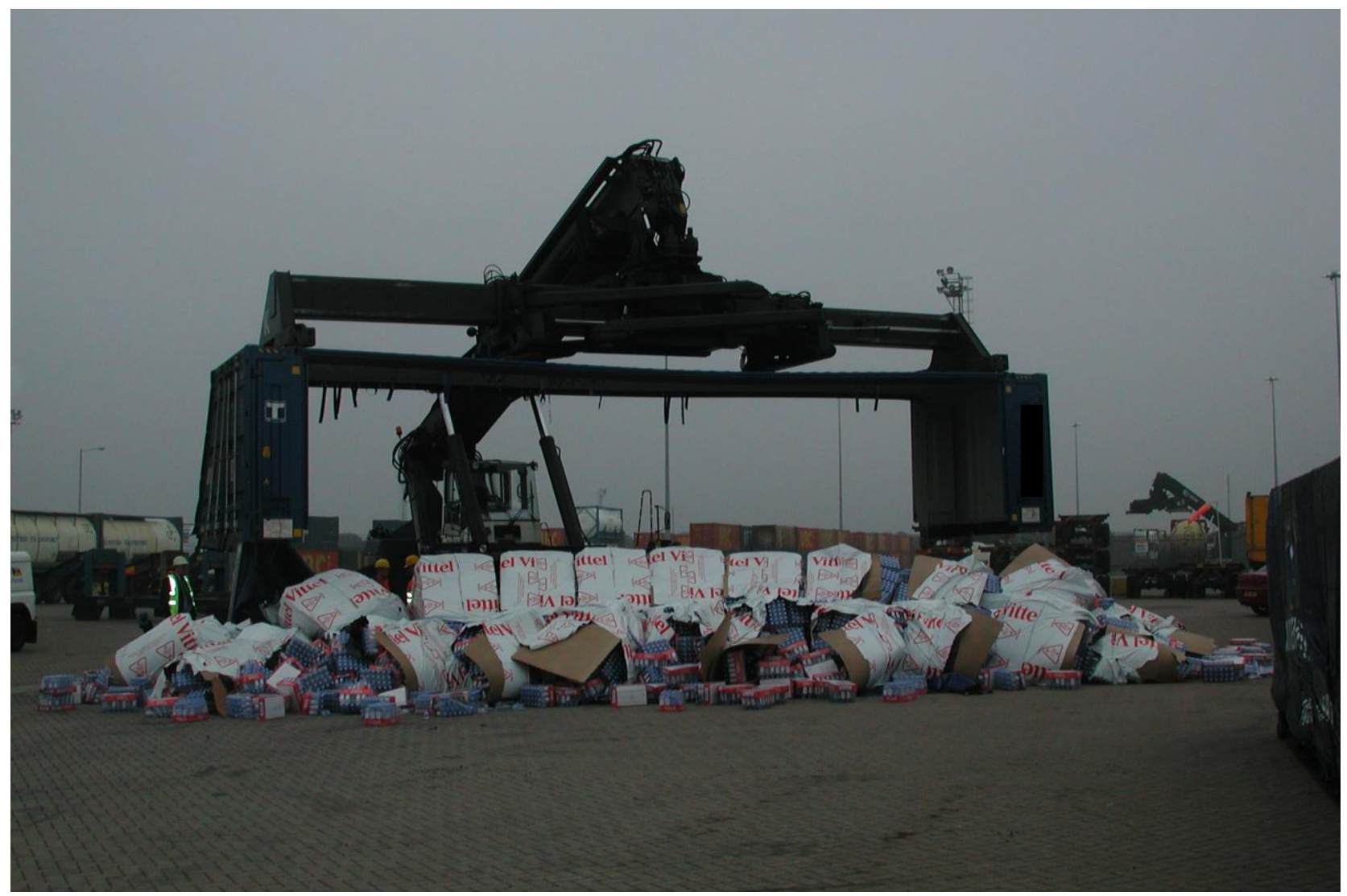

Figure 1. Overview of the failed freight container 
During the handling of a $45 \mathrm{ft}$. container loaded with about 20 tons of bottled mineral water the floor of the container gave way, spilling its contents on the quay floor (see figure 1). The container was not the standard type with corrugated sheet metal sides, but a so called "curtain sider" container in which both sides of the container were equipped with sliding curtains, enabling the easy loading and unloading of the container.

\section{THE INVESTIGATION}

\subsection{Freight container design}

The container was of recently introduced type, which design was based on the time proven design of a $40 \mathrm{ft}$. curtain sider container. To lengthen the container to $45 \mathrm{ft}$., sections of $2.5 \mathrm{ft}$. were added to the front and the back of the existing $40 \mathrm{ft}$. design. The curtains used at both sides of the container were kept at a length of $40 \mathrm{ft}$. and two doors of $2.5 \mathrm{ft}$. were added at both ends of the container. To ensure that the container could be handled using equipment designed for $40 \mathrm{ft}$. freight containers the corner castings of the $40 \mathrm{ft}$. design were retained and extra corner castings at both ends were added to ensure that the $45 \mathrm{ft}$. container could be locked onto trailers designed for $45 \mathrm{ft}$. freight containers.

This resulted in the design shown in figure 2 and 3 . In these figures the freight container is shown on a 40ft. handling trailer called a "MAFI" after the company manufacturing these trailers;

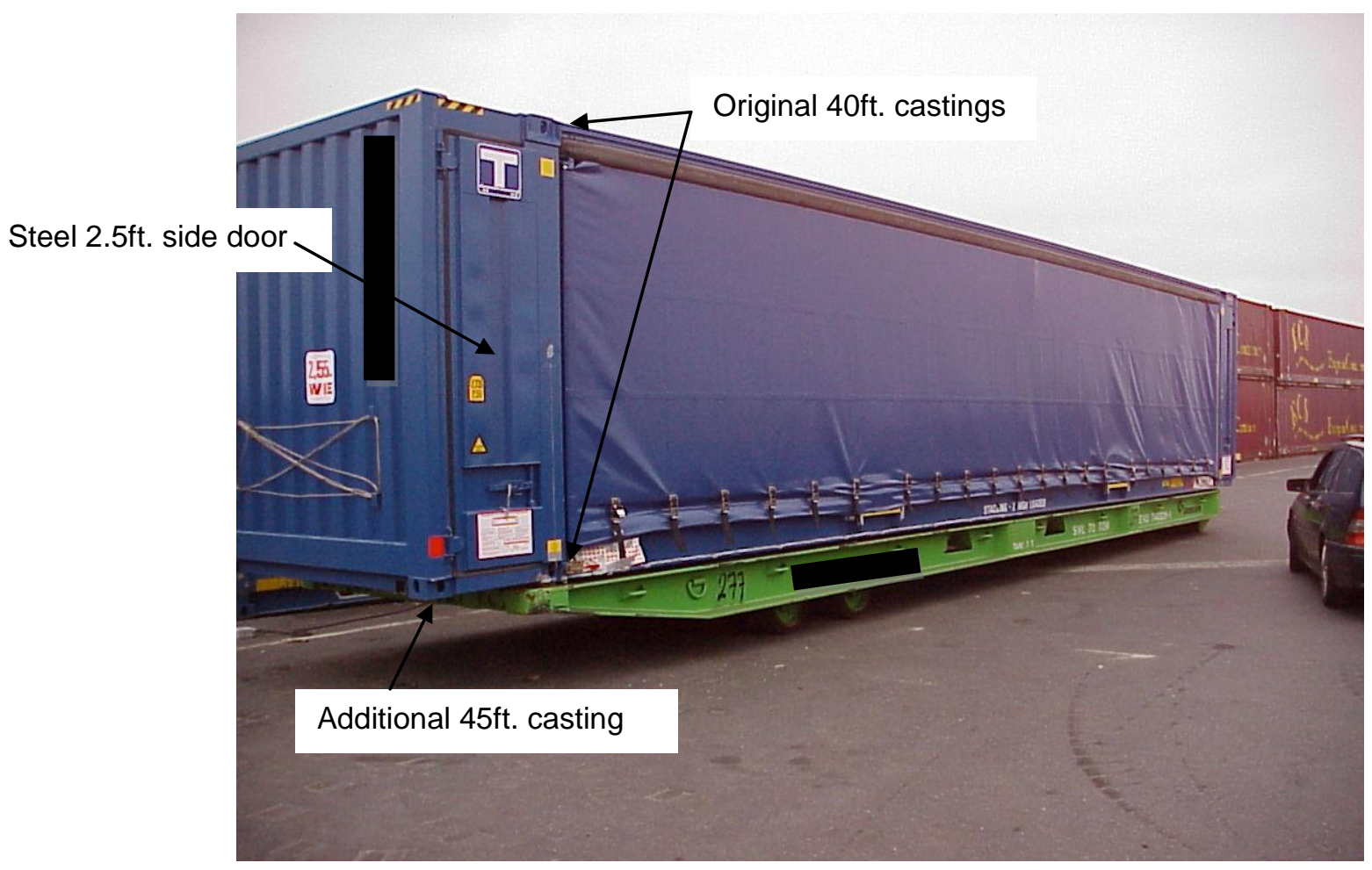

Figure 2. View from the front of a container of the same type, on a 40ft. handling trailer.

\subsection{Design quirks}

When lengthening the design of the container from $40 \mathrm{ft}$. to $45 \mathrm{ft}$. the designer considered that the freight container would be handled mostly with the original castings interspersed by $40 \mathrm{ft}$. (see figure 4). Consequently the extra $2.5 \mathrm{ft}$. of container floor added at the front and the back were manufactured considerably weaker (and lighter) than the original 40ft. container floor in between. To make lifting the container at the 40ft. castings possible the steel doors were strengthened with a vertical girder and equipped with pins at the bottom and at the top of the door, which engaged with the 40ft. castings in the roof and the floor of the container, thus transferring the weight placed on the floor towards the $40 \mathrm{ft}$. castings in the roof.

Due to this design strategy the weight of the container could be limited (the front and back 2.5 floor and roof additions were relatively light). However there was some danger inherent to this design - as the girders in the doors carried the load placed on the floor the doors should always be closed when lifting the container from the top. To notify handlers of this a warning sign to this effect was placed on all four doors. 


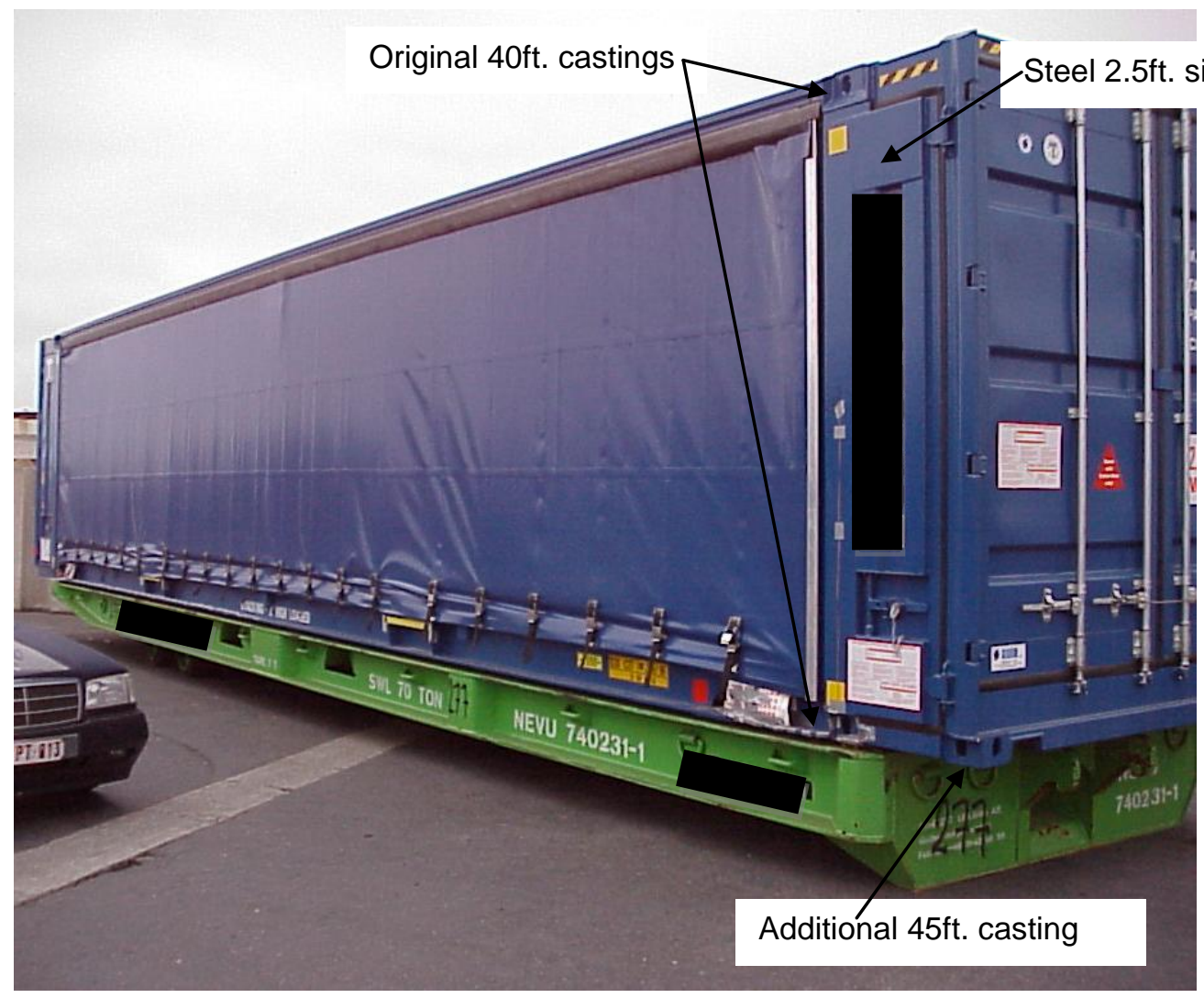

Figure 3. View from the back of a container of the same type on a 40ft. handling trailer

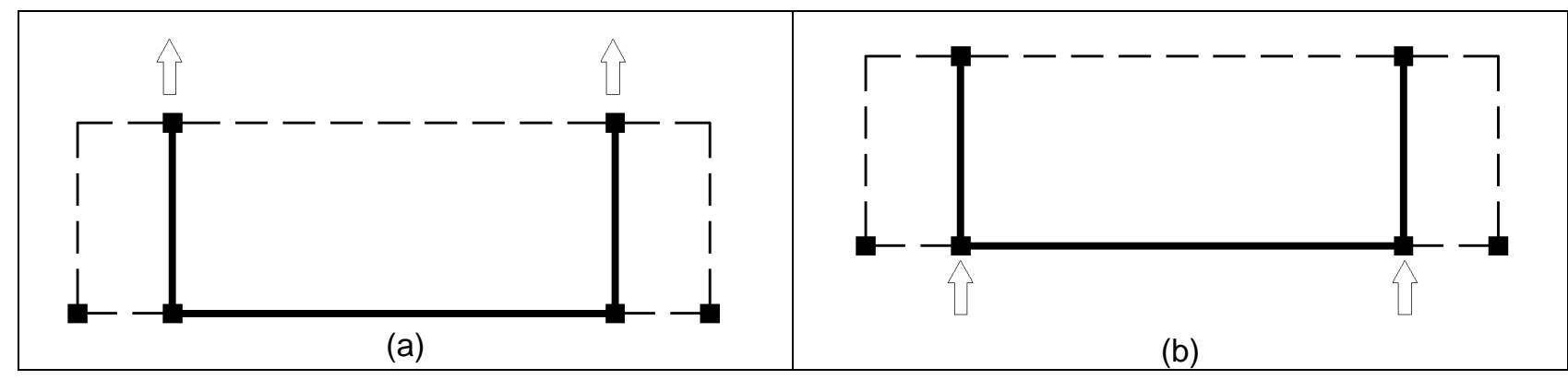

Figure 4. Loading situation considered in the design (a) lifting at the 40ft. castings (b) supported at $40 \mathrm{ft}$. castings.

\subsection{Conditions of use.}

The accident occurred when the container was lifted from the top at the 40ft. castings (see figure 1). Initially some concerns were raised whether the side doors were closed and locked when the container was lifted from the top. The operator of the handling equipment was adamant that the side doors were closed. This was backed up by pictures taken immediately after the accident showing that the doors (which weren't wrenched open in the accident) were still closed and that the pins at the top of the door were still engaged with the castings (see for example figure 5).

Nevertheless the way in which the container floor failed at the back side of the container (see figure 6) clearly indicate the side doors failed before the floor dropped out of the container. The $2.5 \mathrm{ft}$. floor addition is twisted upwards and the beams in the floor are halfway torn from the $40 \mathrm{ft}$. and $45 \mathrm{ft}$. castings. 


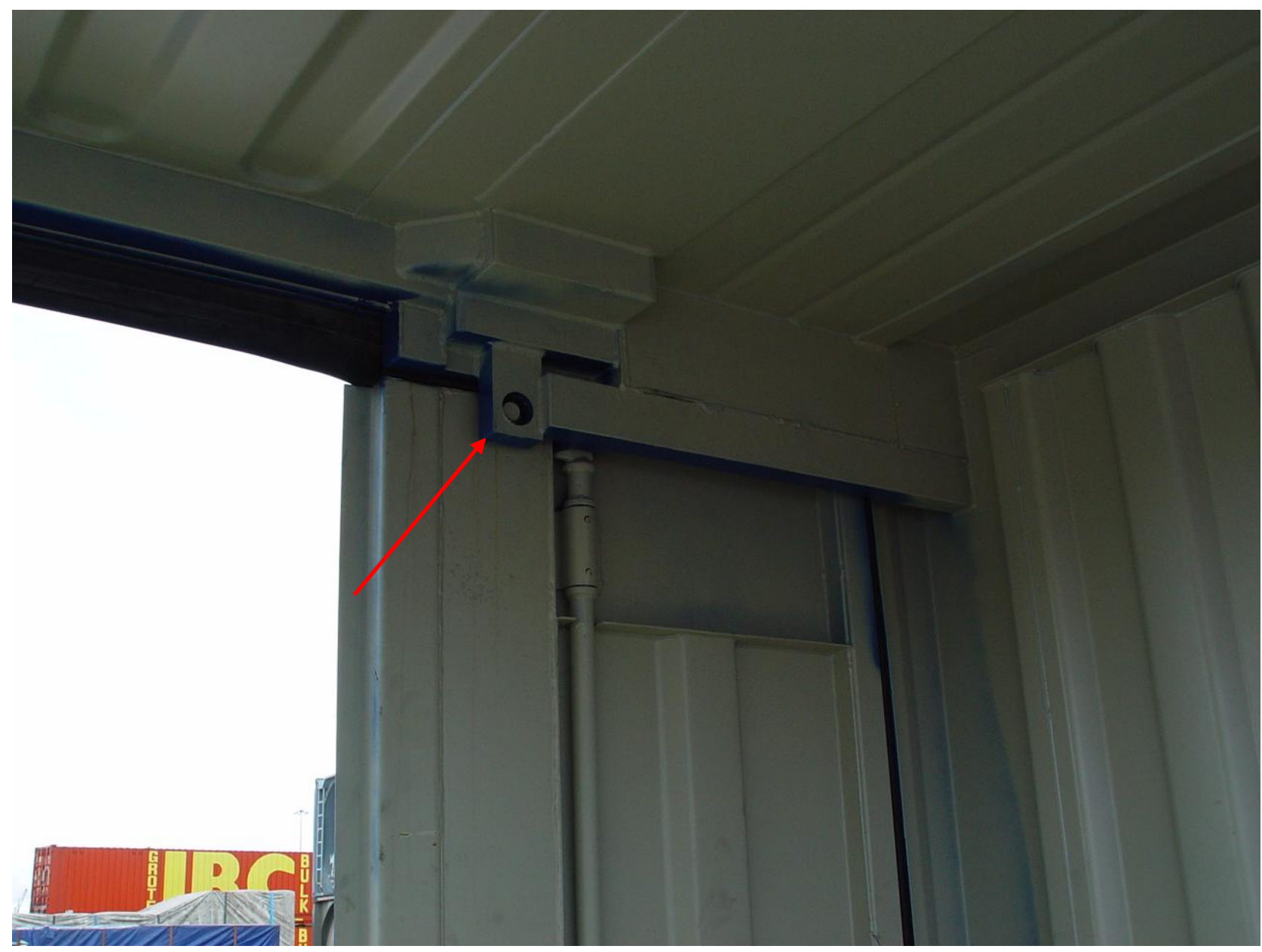

Figure 5. Top of one of the side doors (view from inside container) showing the top pin still connected to the 40ft. casting.

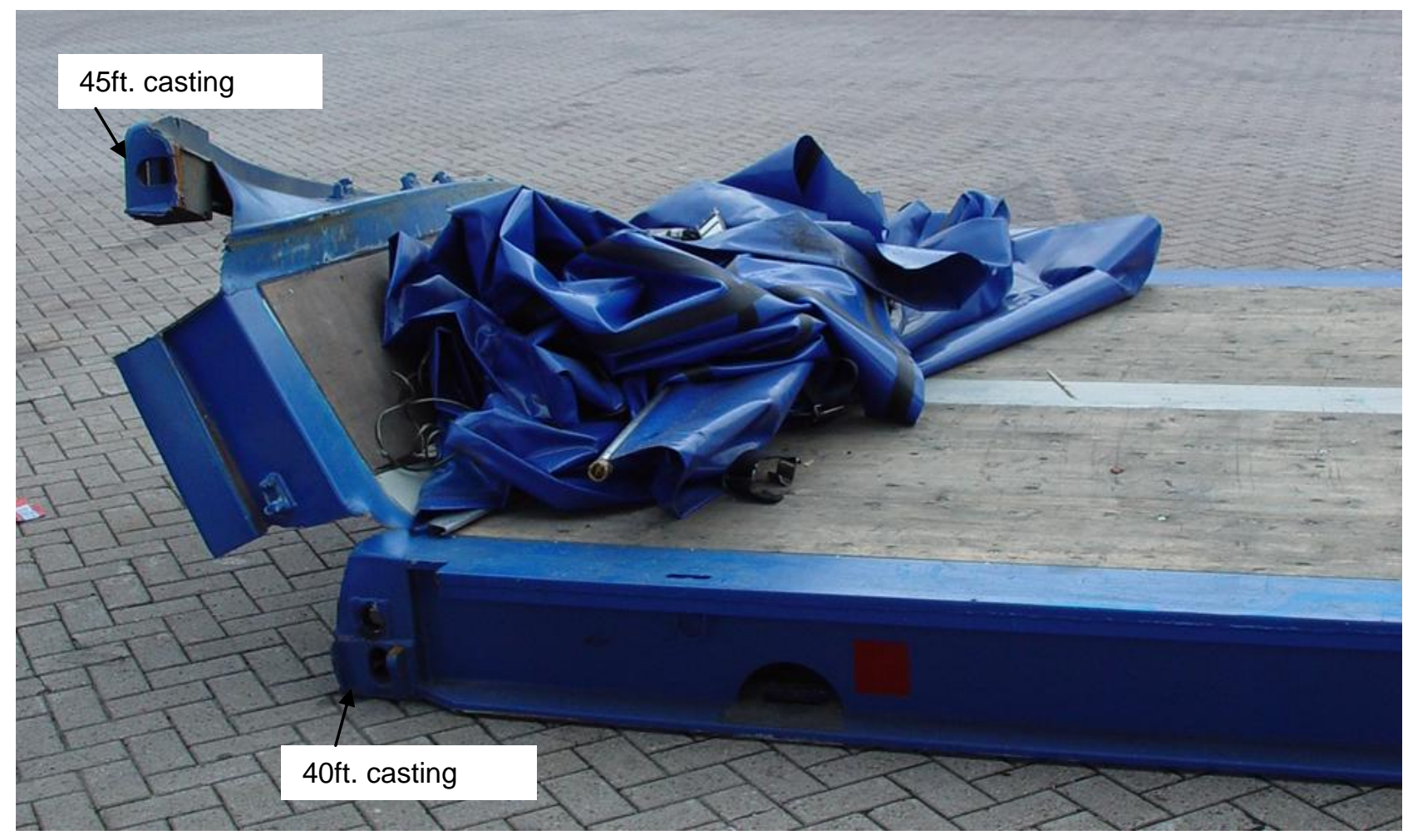

Figure 6. View of the back of the floor. 
The reason for this became evident when the doors were inspected. The pins connecting the bottom of the doors to the 40ft. castings in the floor of the container were badly bent. Something similar occurred to the pins of the side doors at the front of the container: the bottom pin of the right side door was missing and the bottom pin of the left side door was badly bent. Corrosion of the fracture faces indicated that the tears at the connection of the bottom pins to the doors shown in figure 6(b) had occurred sometime prior to the accident. Similar corrosion on the fracture surface of the missing pin shown in figure 7 proved that this pin had already gone missing before the accident, explaining the fact that this pin could not be retrieved at the site of the accident.

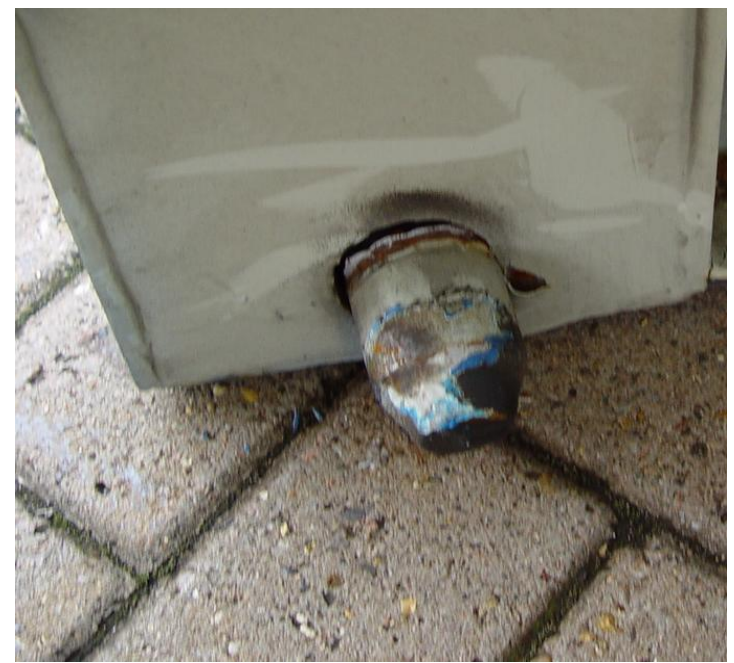

(a)

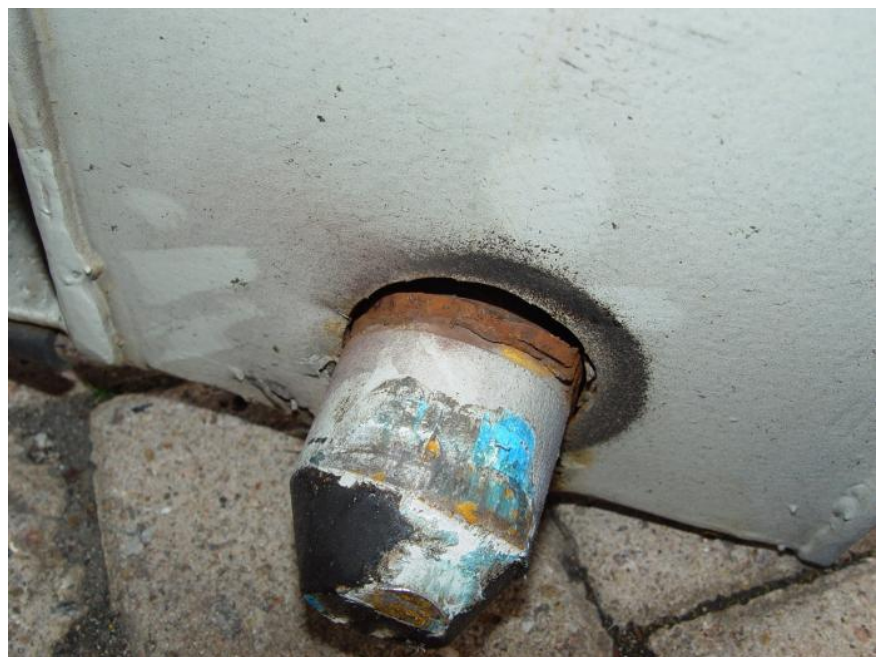

(b)

Figure 6 . View of the bottom pins at the of the side doors at the back of the container: (a) bottom pin of right side door (b) bottom pin of left side door.

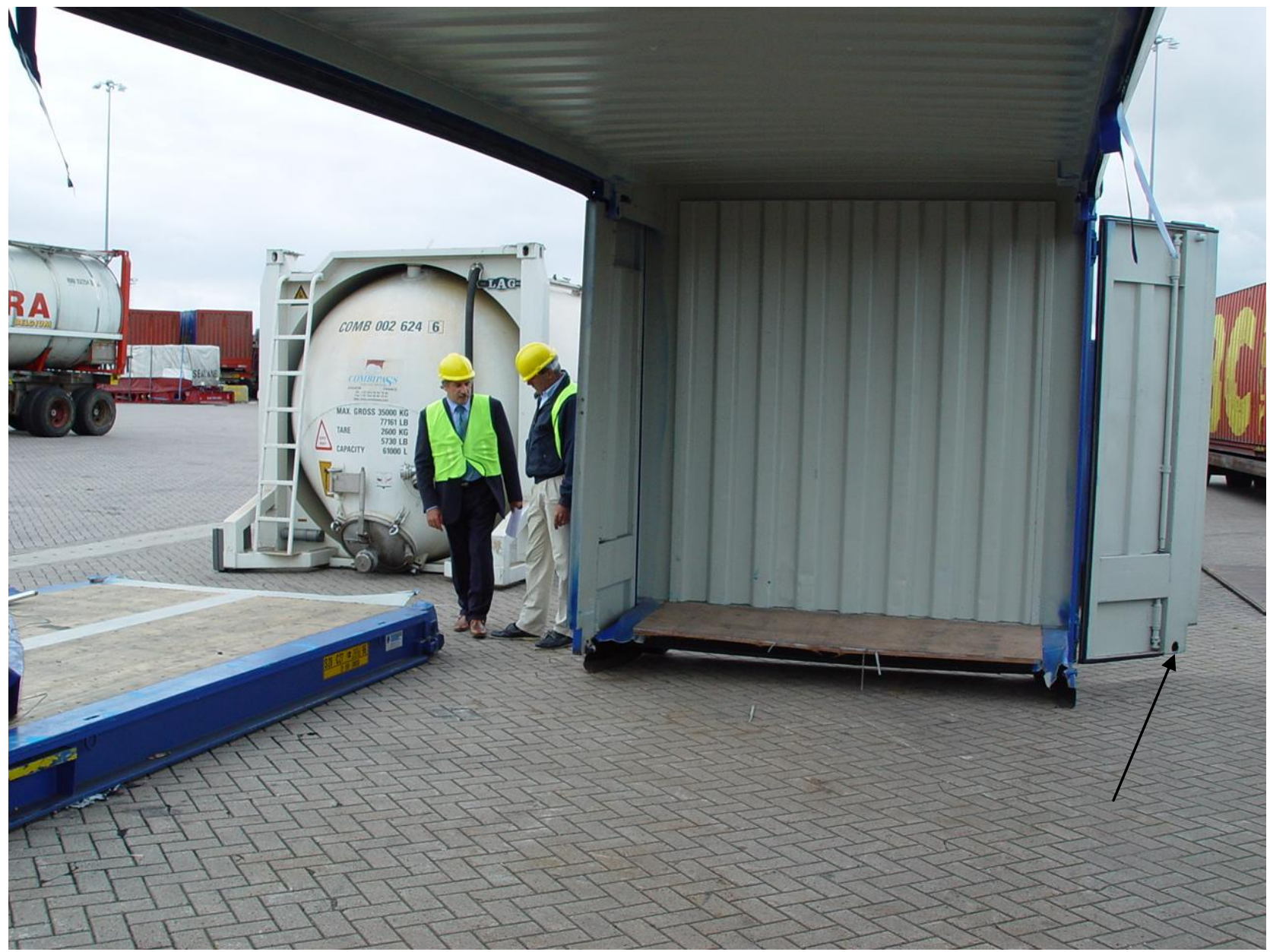

Figure 7. View of the front side of the container. Notice the bottom pin of the right hand side door is missing. 
Due to the failure of the bottom pins of the doors transferred the load from the doors to the $2.5 \mathrm{ft}$. addition on both ends of the container. As these additions were never designed to withstand this load they failed and the floor dropped out of the container.

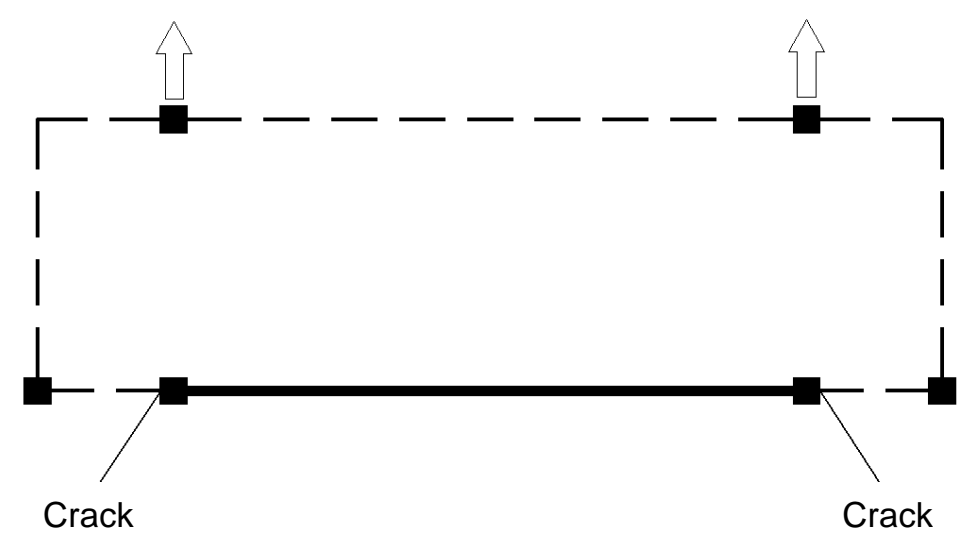

Figure 8. Schematic overview of the condition of the container at the time of the accident. Due to pin failure the doors did not carry any load.

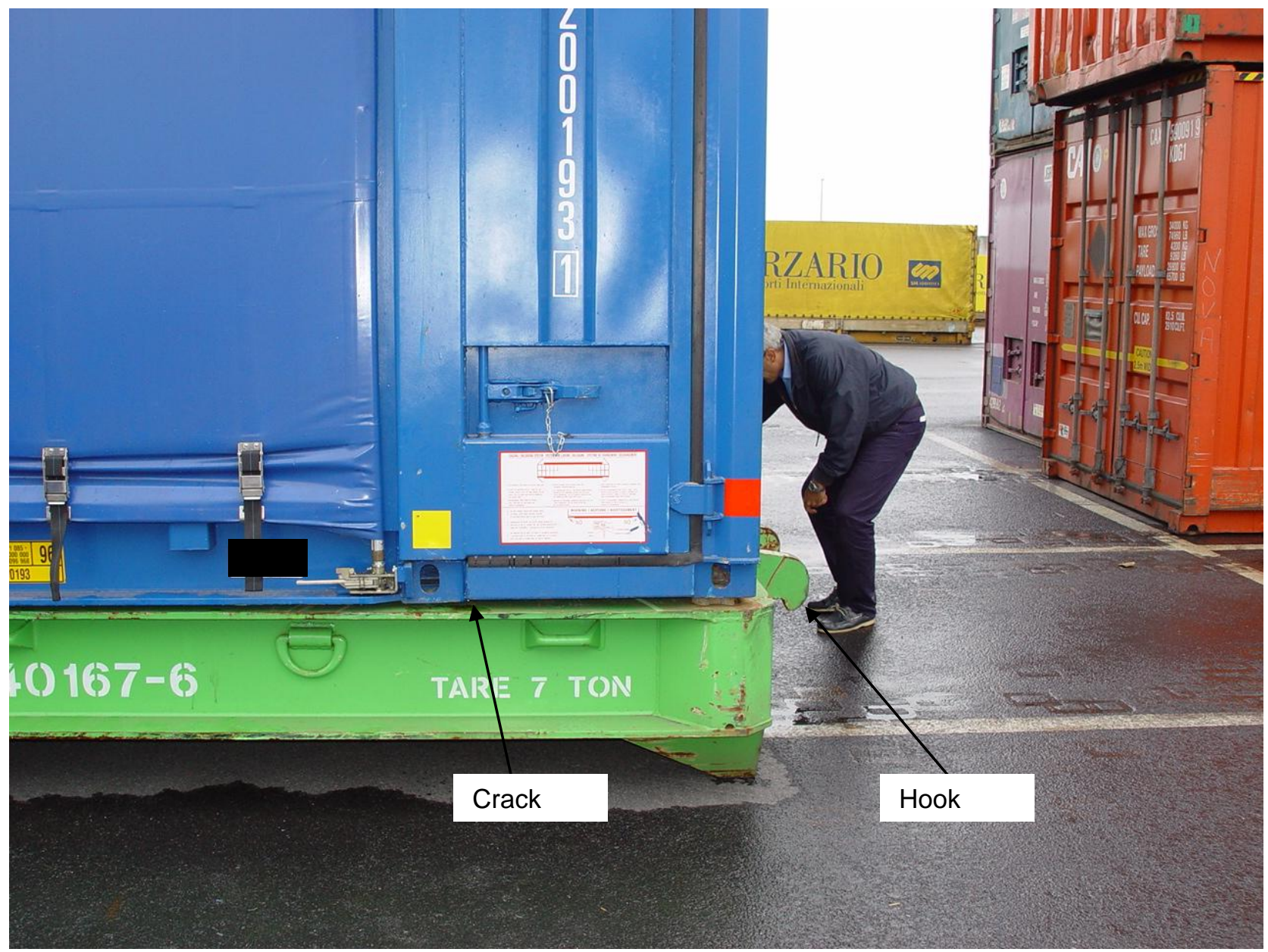

Figure 9. Side view of a similar container on a handling trailer - notice placement on the trailer so that hook is available.

\subsection{Solution}

So it is clear that the failure of the floor resulted from the failure of the pins. This resulted from a design error. At the time of the accident one of the bottom pins was already missing and the one other was half torn from the bottom of the door.

However this design flaw could be easily remedied by strengthening the connection of the pin to the door. But just locally strengthening the doors and the pins will not produce a good design. This is illustrated by the condition of another container which was in use on the quay. Figure 9 shows this container on a handling trailer. First notice that the floor of the $2.5 \mathrm{ft}$. addition contains a large crack which will in a short 
time frame lead to failure (see detail in figure 10). Secondly notice the placement of the container on the handling trailer. The hook at the front of the handling trailer needs to be available to lift this end of the trailer off the ground.

This means that the $2.5 \mathrm{ft}$. floor additions at both ends of the container can be carrying the full weight of the freight in the container and that the design assumptions of figure 4 are erroneous. The load cases shown in figure 11 should have been considered in the design stage.

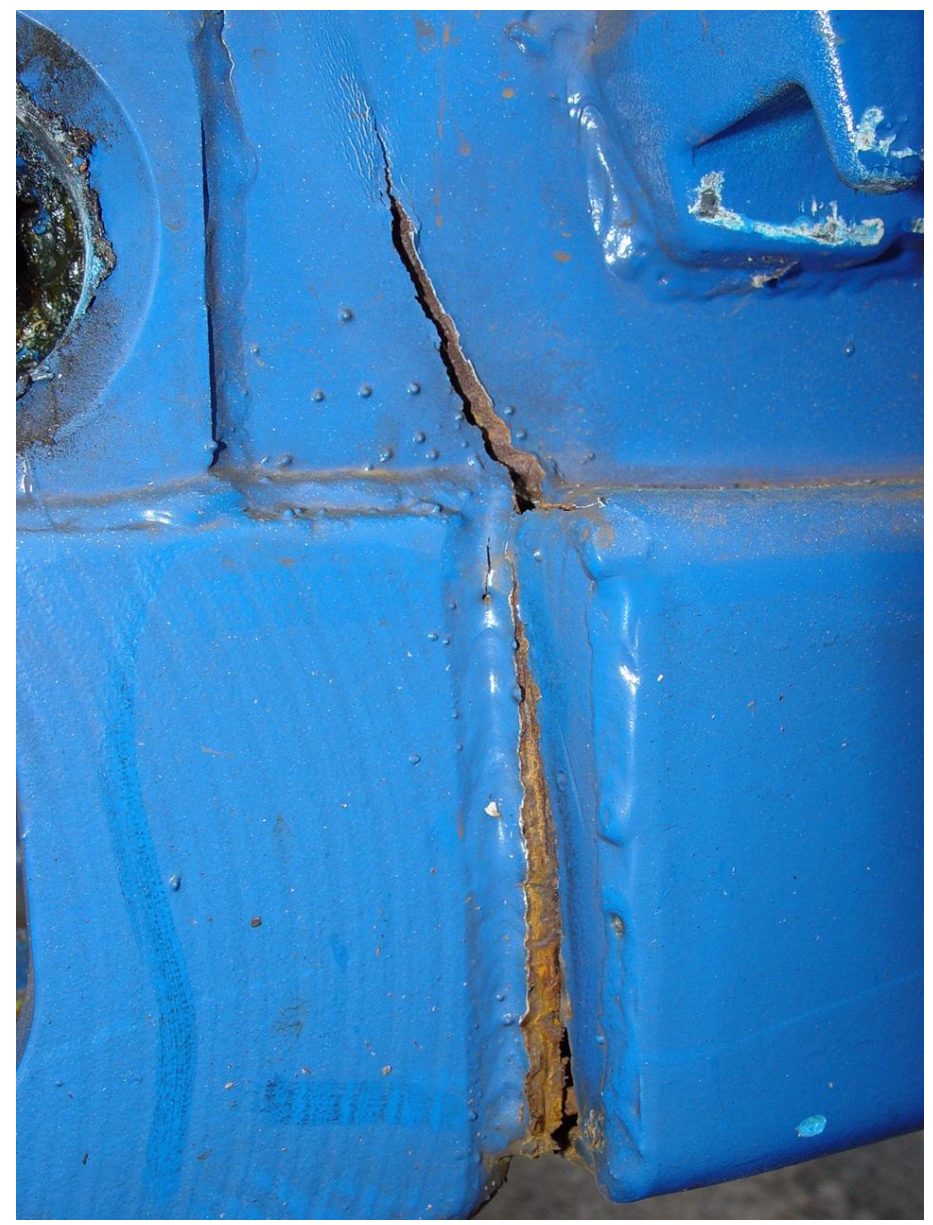

Figure 10. Detail of crack in floor beam of $2.5 \mathrm{ft}$. addition just next to $40 \mathrm{ft}$. casting.

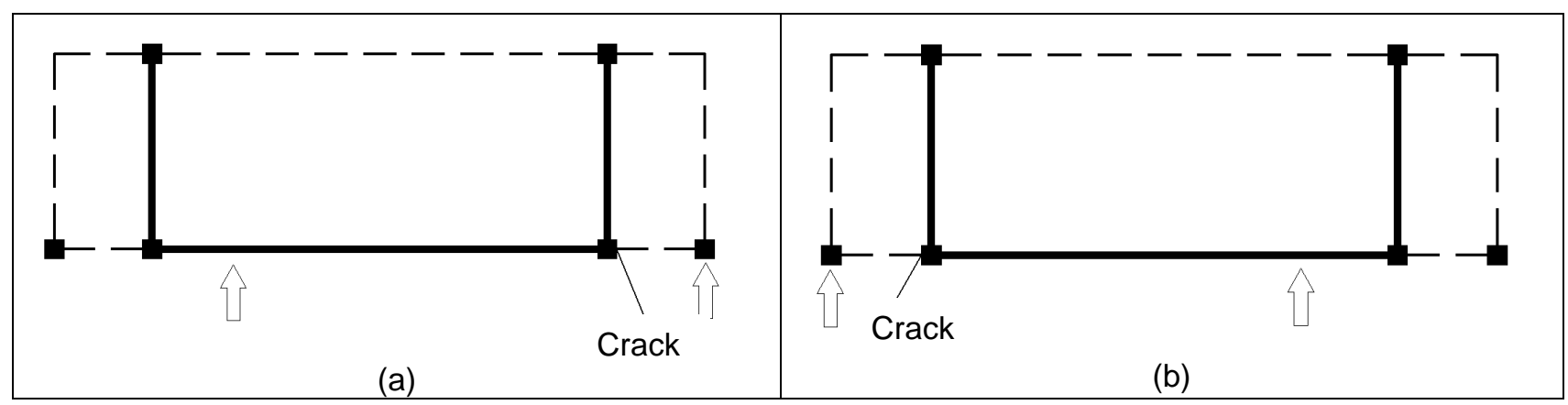

Figure 11. Load situation when the $45 \mathrm{ft}$. freight container is placed on a $40 \mathrm{ft}$. handling trailer. Container will overhang the trailer by $5 \mathrm{ft}$. at one end.

\section{CONCLUSIONS}

Although the design of the freight container exhibited a number of flaws (too weak connections of locking pins to side doors) the failure of these containers was ultimately produced by a quirky design in combination with the conditions under which these containers were used. When a loaded 45ft. container was placed asymmetrically on a 40ft. handling trailer this introduced stresses in the $2.5 \mathrm{ft}$. floor overhang which were not taken into account in the design of the freight container. A redesign of the container floor is necessary. The floor should be able to withstand the stresses introduced by the load when the container is only supported at both $45 \mathrm{ft}$. corner castings. 